\title{
Ranking Alternative Production Scenarios Using Super-Efficiency Analysis
}

\author{
S. Sofianopoulou \\ Department of Industrial Management \& Technology, University of Piraeus \\ 80 Karaoli \& Dimitriou str., 18534 Piraeus, Greece \\ e-mail:sofianop@unipi.gr
}

\begin{abstract}
The modern, particularly competitive and demanding operational environment has led many companies to a continuous effort for implementing techniques and evaluating alternative production scenarios, which will allow them to optimize their production processes and reduce their cost. In this study, a consumer goods manufacturing company was selected to implement modern optimization techniques in its production processes and then to evaluate the efficiency of potential changes on its operation as well as to record the problems and difficulties arising in such a case. Data Envelopment Analysis, a linear programming based technique was employed to evaluate the efficiency of twelve alternative production layout scenarios. Those scenarios were created through the application of advanced Group Technology techniques and some basic indices/characteristics were attached to each one of those layouts. Results indicated that more than one of these scenarios can be effective. An additional analysis for ranking those scenarios was conducted using the superefficiency model. According to the results of this study, nine of the proposed scenarios are efficient and thus significant improvements can be achieved in the system's performance, without actually changing its basic production parameters. It is concluded that both the results of the evaluation and the experience gained during the implementation phase, can be very useful for supporting the goals and decisions of the company.
\end{abstract}

Keywords: - Manufacturing cells, efficiency assessment, data envelopment analysis, super-efficiency

\section{INTRODUCTION}

Today's markets are characterized by the consumers' demand for an ever-greater variety of products in smaller quantities. Under these conditions maintaining high efficiency in batch operations of traditional, process oriented, manufacturing facilities is very difficult. A technique which overcomes most of the usual problems met in the traditional production systems is Group Technology (GT) [1]. GT is a manufacturing philosophy that organizes and uses information for grouping various parts and products with similar machining requirements (and/or design characteristics) into families of parts and corresponding machines into machine cells. The main objective of cellular manufacturing is to construct machine cells, to identify part families and ultimately to allocate part families to machine cells so as to minimize interaction among different cells [2], [3], [4], [5]. This way, a number of manufacturing cells are constructed. With the implementation of cellular manufacturing, GT is capable of improving productivity and reducing costs in batch production so that it becomes comparable to those of mass production. Fully independent machine cells, however, are rare in practice. Some parts need to be processed by more than one machine cell, inevitably leading to a number of intercellular moves. These parts are appropriately termed as "exceptional" parts, while machines processing them, as "bottleneck" machines. The designer of such systems, who tries to allocate machines to cells in such a way so to keep the interaction among cells to the lowest possible level, i.e. to cut down the presence of exceptional parts. The application of cellular manufacturing results in shorter work-in-process lead times, greater job satisfaction (workers are trained to operate several different machines within a cell) as well as decreased cost and set up times of production lines (different product families are manufactured with the same or similar set up requirements).

The majority of research focuses in the cell formation process using as main criterion the interaction among cells, i.e. the number of intercellular moves. Given a cell formation procedure, alternative cellular manufacturing layouts can be formed, using the above criterion, by differentiating the number of machines (some machine types can be easily replaced by others), the number of cells to be formed or the number of machines per cell. Evaluation of alternative cellular manufacturing layouts (scenarios) requires comparison of several parameters involved in the implementation and operation of each scenario on the shop floor.

Among different evaluation techniques, Data Envelopment Analysis (DEA) is a methodology that assesses the performance of each layout considered in a non-arbitrary manner. It is flexible enough to accommodate any parameters that are significant to the system under assessment and can provide the decision maker with guidelines and suggestions on how each inefficient scenario can be improved in terms of the parameters involved in the evaluation.

The objective of this paper is to illustrate how DEA has been used to evaluate twelve different cellular manufacturing configurations in a Greek manufacturing company. The behaviour of the production system was observed for long periods in order to determine the factors that affect or describe its efficiency. However, because collection of data was impossible in real-time conditions, simulation technique was employed to run each 
production scenario and collect the necessary data corresponding to each one of the different cellular manufacturing layouts. The DEA method is briefly introduced and consequently applied in the particular test case. The super-efficiency model is next employed to rank efficient scenarios. Computational results included in the paper indicate that DEA is a very useful tool in the hands of decision makers.

\section{DATA ENVELOPMENT ANALYSIS}

In recent years DEA has been utilized in a great variety of applications for evaluating the performance of different systems. Through DEA it has also been possible to gain new insight into systems that until then were extremely complicated to study because of the number of parameters involved. DEA employs mathematical programming techniques to evaluate the efficiency of homogeneous decision making units (DMU), where DMUs can be bank branches, retail stores, hospital units etc. The efficiency is translated as the ratio of the weighted sum of outputs to the weighted sum of inputs. In our test case, the heart of the analysis lies in finding the best virtual cellular manufacturing layout for each given layout. If the virtual layout is better than the given one in terms of making more output with the same input or using less input for the same output then the given layout is considered to be inefficient. The procedure of finding the best virtual DMU can be formulated as a linear program. Assessing the performance of $n$ different DMUs involves the solution of $n$ different linear programming problems.

Charnes, Cooper and Rhodes [6] in 1978 proposed one of the most basic DEA models, appropriately termed as the CCR model. Given that there are n DMUs and associated numerical data for each of the $m$ inputs and $s$ outputs for all DMUs, the fractional mathematical programming problem that is solved in order to obtain values for the input weights $\left(\boldsymbol{v}_{i}\right)(i=1, \ldots, m)$ and the output weights $\left(\boldsymbol{u}_{r}\right)(r=1, \ldots, s)$ variables is the following [7]:

$$
\max \boldsymbol{z}=\frac{\sum_{r=1}^{s} \boldsymbol{u}_{r} \boldsymbol{y}_{r j_{0}}}{\sum_{i=1}^{m} \boldsymbol{v}_{i} \boldsymbol{x}_{i j_{0}}}
$$

subject to

$$
\frac{\sum_{r=1}^{s} \boldsymbol{u}_{r} \boldsymbol{y}_{r j}}{\sum_{i=1}^{m} \boldsymbol{v}_{i} \boldsymbol{x}_{i j}} \leq 1 \quad(j=1, \ldots, n)
$$

$$
\boldsymbol{u}_{r} \geq 0, \quad(r=1, \ldots, s)
$$

$$
\boldsymbol{v}_{i} \geq 0, \quad(i=1, \ldots, m)
$$

Index $\mathrm{j}_{0}$ refers to the DMU being evaluated. Objective function (1) maximizes the ratio of virtual output to virtual input of the DMU under evaluation by calculating the appropriate weights $\boldsymbol{v}_{i}$ and $\boldsymbol{u}_{r}$. Constraints (2) ensure that this ratio does not exceed 1 for every DMU. This implies that the objective function value lies between 0.0 and 1.0; the latter value denoting that the DMU under examination is efficient. The above non-linear program is linearized and the solution of its linear equivalent produces the efficiency scores for all DMUs. This study adopts the input-oriented CCR-DEA model. The inputoriented model optimizes the input usage while the outputs are fixed. The model shows the result in between 0 to 1 , where a ratio equal to 1 means the unit is efficient, while with a value less than 1 is considered as relatively inefficient. The CCR model reflects the relative efficiency without scale adjustment.

\section{CASE STUDY}

The DEA evaluation technique was applied on an actual data set from the production system of a manufacturing company. Particular characteristics of this market are short product life cycles, fluctuations in demand and frequent changes in products packaging. In order for the system to be able to meet the above requirements it should be organized in flexible production lines that produce small batches of products over short periods of time.

In the present work, the efficiency of 12 alternative cellular manufacturing configurations is evaluated. The DEA model validated a former project undertaken for adopting cellular manufacturing configuration in the production process of the particular manufacturing company. The data collected consists of 891 products using up to 19 machine types, where each machine type could have several identical replicates. Machine sequence operations were taken into account in the formation of machine cells. A simulated annealing algorithm which has been proposed by the author [4] was employed to develop the 12 alternative cellular manufacturing configurations. These 12 scenarios were created by varying: a) the number of machine types utilized b) the maximum number of machines allowed per cell and c) the volume of production. For each one of these scenarios a discrete simulation model was run for a period of two years using the commercial simulation software package SIMFACTORY by CACI Inc. The simulation runs performed for each scenario produced results for seven performance indices that are presented in Table I and subsequently formed the basic data for the DEA evaluation. 
TABLE I

ALTERNATIVE CELLULAR CONFIGURATIONS AND CORRESPONDING INPUTS AND OUTPUTS

\begin{tabular}{|c|c|c|c|c|c|c|c|}
\hline & TM & TW & AWIP & AMKSP & AMU & AWU & AST \\
\hline DMU1 & 24 & 49 & 0 & 499 & 65.2 & 67.1 & 0.00 \\
\hline DMU2 & 26 & 54 & 74653 & 1703 & 61.6 & 59.9 & 4.40 \\
\hline DMU3 & 25 & 50 & 83799 & 2948 & 60.5 & 60.4 & 5.74 \\
\hline DMU4 & 24 & 50 & 81125 & 2874 & 63.4 & 62.1 & 4.14 \\
\hline DMU5 & 25 & 50 & 111650 & 2575 & 60.2 & 60.7 & 5.58 \\
\hline DMU6 & 26 & 58 & 79574 & 2890 & 62.7 & 60.1 & 1.57 \\
\hline DMU7 & 24 & 48 & 91576 & 0 & 63.7 & 64.6 & 4.83 \\
\hline DMU8 & 24 & 51 & 66290 & 3472 & 63.7 & 60.4 & 4.23 \\
\hline DMU9 & 25 & 56 & 56200 & 1748 & 65.2 & 61.5 & 0.72 \\
\hline DMU10 & 23 & 50 & 53936 & 1703 & 67.8 & 64.9 & 2.85 \\
\hline DMU11 & 24 & 51 & 72154 & 4008 & 64.1 & 63.0 & 3.84 \\
\hline DMU12 & 25 & 50 & 111650 & 2575 & 60.2 & 60.7 & 5.58 \\
\hline
\end{tabular}

In Table I, columns TM and TW refer to the number of machines used and workers/operators hired to operate the machines. These two columns form the inputs for the DEA evaluation, while data columns 3-7 represent the outputs. For both inputs it is assumed that smaller values correspond to better cellular configurations. The third data column refers to the average work-in-process inventory (AWIP), which concerns products in various stages of production. Column AMKSP refers to the average makespan which together with output index AWIP are of major importance for the assessment of a production system. Columns AMU and AWU contain data for the average machine and worker utilization respectively. Last column AST refers to average machine setup times.

DEA method assumes that all outputs considered should be as high as possible for a DMU. Since this is not valid for outputs AWIP and AMKSP, the data in those two columns have been transformed so that the usual assumption would also be followed here. The transformation was achieved by subtracting the original value produced by the simulation runs for AWIP or AMKSP from the corresponding maximum value found among all DMUs.

\section{DEA MODEL}

The DEA methodology was applied in the data of Table I using the CCR model and the results produced are presented in Tables II and III.

Table II depicts the efficiency scores of the twelve different scenarios considered. As it can be seen, nine of the twelve scenarios are efficient (efficiency scores are equal to 1.0). Looking more carefully at the inputs and outputs of the inefficient DMUs, one can observe that they require more production resources from the two inputs, compared to the other DMUs, without however producing more output. Namely, scenarios DMU2, DMU6 and DMU9 employ 26 machines and 54 operators, 26 machines and 58 operators, 25 machines and 56 operators respectively, without producing significantly better results.

TABLE II

EFFICIENCY SCORES OF CELLULAR MANUFACTURING CONFIGURATIONS

\begin{tabular}{|l|l|l|l|}
\hline DMU1 & 1.000 & DMU7 & 1.000 \\
\hline DMU2 & 0.894 & DMU8 & 1.000 \\
\hline DMU3 & 1.000 & DMU9 & 0.898 \\
\hline DMU4 & 1.000 & DMU10 & 1.000 \\
\hline DMU5 & 1.000 & DMU11 & 1.000 \\
\hline DMU6 & 0.911 & DMU12 & 1.000 \\
\hline
\end{tabular}

Table III presents the reference set for each inefficient DMU. In this table each column corresponds to an efficient DMU. The reference set is formed by those efficient DMUs that can act as models (i.e. DMUs that correspond to columns with non-zero elements) for the inefficient ones. For each row, therefore, in Table III weights are assigned to efficient DMUs in order to form a virtual/model DMU to which the corresponding inefficient one should resemble. Thus, the reference set of inefficient DMU2 consists of DMU3, DMU7, and DMU8 and in particular DMU2 should use as its model a virtual DMU resembling by $1.4 \%$ to DMU3, by $47.5 \%$ to DMU7, and by $47.8 \%$ to DMU8. Thus, for example as far as any DMU2 input is concerned, DMU2 should reduce the particular input to $0.894 \mathrm{x}$ (Input of DMU2) $=0.014 \mathrm{x}$ (Input of DMU3) $+0.475 \times$ (Input of DMU7) $+0.478 \times$ (Input of DMU8).

TABLE III

REFERENCE SETS

\begin{tabular}{|c|c|c|c|c|c|c|c|c|c|}
\hline $\mathrm{DMU}$ & $\mathbf{1}$ & $\mathbf{3}$ & $\mathbf{4}$ & $\mathbf{5}$ & $\mathbf{7}$ & $\mathbf{8}$ & $\mathbf{1 0}$ & $\mathbf{1 1}$ & $\mathbf{1 2}$ \\
\hline $\mathbf{1}$ & 1.000 & & & & & & & & \\
\hline $\mathbf{2}$ & & 0.014 & & & 0.475 & 0.478 & & & \\
\hline $\mathbf{3}$ & & 1.000 & & & & & & & \\
\hline $\mathbf{4}$ & & & 1.000 & & & & & & \\
\hline $\mathbf{5}$ & & & & 1.000 & & & & & \\
\hline $\mathbf{6}$ & & & & 0.333 & & & 0.250 & 0.401 & \\
\hline $\mathbf{7}$ & & & & & 1.000 & & & & \\
\hline $\mathbf{8}$ & & & & & & 1.000 & & & \\
\hline $\mathbf{9}$ & & & & 0.062 & & & 0.889 & 0.019 & \\
\hline $\mathbf{1 0}$ & & & & & & & 1.000 & & \\
\hline $\mathbf{1 1}$ & & & & & & & & 1.000 & \\
\hline $\mathbf{1 2}$ & & & & & & & & & 1.000 \\
\hline
\end{tabular}




\section{SUPER-EFFICIENCY MODEL}

The CCR model splits the DMUs into inefficient and efficient ones. However, as all efficient DMUs have an efficiency score of 1 , it is not possible to grade efficient DMUs. Andersen and Petersen [3] proposed the super-efficiency ranking method for efficient DMUs. The super-efficiency model is a DEA model where a DMU under evaluation is excluded from the reference set. This allows a DMU to move above the efficient frontier, to become superefficient. Therefore, efficient DMUs take a superefficiency score with any value greater than or equal 1. This procedure produces a ranking of efficient DMUs where the higher the value the higher the rank, while, the scores for inefficient DMUs remain the same as in the classical DEA models.

The super-efficiency model was employed to rank efficient DMUs, i.e., efficient cellular manufacturing configurations. The results are presented in Table IV. In order to decide the rank of each DMU in the view of overall technical efficiency, it attempts to measure super-efficiency scores in input-oriented CCR model.

TABLE IV

RANKING/SUPER-EFFICIENCY SCORES OF CELLULAR MANUFACTURING CONFIGURATIONS

\begin{tabular}{|c|c|c|c|}
\hline DMU11 & 1.154 & DMU4 & 1.001 \\
\hline DMU10 & 1.098 & DMU5 & 1.000 \\
\hline DMU7 & 1.083 & DMU12 & 1.000 \\
\hline DMU3 & 1.073 & DMU6 & 0.911 \\
\hline DMU1 & 1.028 & DMU9 & 0.898 \\
\hline DMU8 & 1.008 & DMU2 & 0.894 \\
\hline
\end{tabular}

The results depict that the super-efficiency scores of DMUs $11,10,7,3,1,8$ and 4 of which all efficiency indices are equal to 1 , have super-efficiency scores 1.154 , $1.098,1.083,1.073,1.028,1.008$ and 1.001 respectively. Therefore, DMU11 is evaluated as the most efficient. On the other hand one could note that the super-efficiency scores of the inefficient DMUs are the same as the efficiency indices in CCR model, with DMU2 being the most inefficient.

\section{CONCLUSIONS}

In this paper, DEA was employed to evaluate the efficiency of 12 alternative cellular manufacturing layouts/scenarios in a manufacturing company with respect to seven performance indices -2 inputs and 5 outputs. DEA results demonstrated that several efficient layouts exist. Additionally, the ranking of the efficient DMUs was identified by using the super-efficiency model. On the other hand, as far as the inefficient scenarios are concerned, guidelines are provided on how to improve and transform them into efficient ones.

\section{REFERENCES}

[1] Burbidge, J L, "The Introduction of Group Technology", Wiley, New York, 1975.

[2] Cheng, C.H., "Algorithms for grouping machine groups in group technology", Omega International Journal of Management Science, vol. 20, 4, pp. 493501, 1992.

[3] Kandiller, L., "A comparative study of cell formation in cellular manufacturing systems", International Journal of Production Research, vol. 32, 10, pp. 2395-2429, 1994.

[4] Sofianopoulou, S, “Application of simulated annealing to a linear model for the formulation of machine cells in group technology" International Journal of Production Research, vol. 35, pp.501-511, 1997.

[5] Spiliopoulos, K. and S. Sofianopoulou, "An optimal tree search method for the manufacturing systems cell formation problem", European Journal of Operational Research, vol. 105, pp. 537-551, 1998.

[6] Charnes, A, W.W. Cooper and E. Rhodes, "Measuring the efficiency of Decision Making Units", European Journal of Operational Research, vol. 2, pp. 429-444, 1978.

[7] Cooper, W.W., L. M. Seiford and K. Tone, "Data Envelopment Analysis: a comprehensive text with models, applications, references, and DEA-Solver software", Kluwer Academic Publishers, 1999.

[8] Banker, R.D., A. Charnes, W.W. and Cooper, "Some models for estimating technical and scale inefficiencies in Data Envelopment Analysis", Management Science, vol. 30, pp.1078-1092, 1984 .

[9] Anderson, P. and Petersen, N.C.. "A Procedure for Ranking Efficient Units in Data Envelopment Analysis", Management Science, Vol. 39, No. 10, pp.1261-1264, 1993. 